\title{
Assessment of disk displacements of the temporomandibular joint
}

\section{Avaliação dos deslocamentos de disco da articulação temporomandibular}

\author{
Ana Carolina Ramos Mariz* \\ Paulo Sérgio Flores Campos** \\ Viviane Almeida Sarmento** \\ Maria Olívia Dias Gonzalez*** \\ Jurandyr Panella**** \\ Carlos Maurício Cardeal Mendes ${ }^{* * * *}$
}

\begin{abstract}
The aim of the present research was to evaluate disk displacements (DDs) of the temporomandibular joint (TMJ) among patients referred for magnetic resonance imaging (MRI) scans, and analyze the type and prevalence of DD, gender, age, side distribution, reciprocal clicking, presence of pain, range of mouth opening movement, and dental condition. The sample comprised 113 patients, 12-78 years old (the age average was $36.4 \pm 13.5$ years), 92 females and 21 males, who underwent MRI between July 2001 and December 2002. A Signa Horizon system (GE) MRI scanner was used at a magnetic field magnitude of $1.5 \mathrm{~T}$ with a bilateral radiofrequency surface coil $(6.5 \times 6.5 \mathrm{~cm})$. Twenty-three $(20.4 \%)$ patients were found to be normal, whereas 90 (79.7\%) presented with DD. Anterior DD (61.1\%) was the most common type of articular disk displacement. Males and females were equally affected (no statistically significant difference). We did not find a statistically significant association between DD and increased age. Bilateral DD (70\%) was the most common DD occurrence. We found a statistically significant association between reciprocal clicking and anterior DD with reduction. We did not find a statistically significant association between DD and pain, be it articular or facial pain, otalgia or cephalgia. We found a statistically significant association between anterior DD without reduction and mouth opening limitation. With regard to oral condition, we did not find a statistically significant association between DD and loss of teeth.
\end{abstract}

DESCRIPTORS: Temporomandibular joint; Magnetic resonance imaging; Temporomandibular joint disk.

RESUMO: Nesta pesquisa, o objetivo foi avaliar os deslocamentos de disco (DDs) da articulação temporomandibular (ATM) de pacientes indicados para ressonância magnética (RM), no que concerne ao tipo e à prevalência do DD, distribuição por sexo, faixa etária e lado, a estalidos articulares (EAs), dor, amplitude do movimento de abertura da boca e condição da dentição. A amostra constou de 113 pacientes, na faixa etária de 12 a 78 anos (média de 36,4 \pm 13,5 anos), 92 do gênero feminino e 21 do gênero masculino, examinados no período de julho de 2001 a dezembro de 2002. Os exames foram procedidos em equipamento modelo Signa Horizon (GE), magnitude do campo magnético de $1,5 \mathrm{~T}$, com bobina bilateral de superficie de 6,5 x 6,5 cm. Vinte e três $(20,4 \%)$ pacientes apresentaram condição de normalidade, enquanto $90(79,7 \%)$ apresentaram-se acometidos por DDs, sendo que DD anterior $(61,1 \%)$ foi o mais prevalente. Indivíduos do gênero feminino e do gênero masculino foram igualmente afetados pela condição (diferença estatística não significante). Não observamos associação estatisticamente significante entre DD e elevação da faixa etária. A ocorrência bilateral de DD (70\%), em relação à ocorrência unilateral, foi mais prevalente. Observamos associação estatisticamente significante entre DD anterior com redução e EA. Não observamos associação estatisticamente significante entre DD e dor, seja articular, facial, otalgia ou cefaléia. Observamos associação estatisticamente significante entre DD anterior sem redução e limitação de abertura de boca. Não observamos associação estatisticamente significante entre DD e perda de dentes.

DESCRITORES: Articulação temporomandibular; Imagem por ressonância magnética; Disco da articulação temporomandibular.

\footnotetext{
* Professor, Department of Propaedeutics and Integrated Clinic, School of Dentistry; **PhDs, Professors, Department of Propaedeutics and Integrated Clinic, School of Dentistry; $* * * *$ PhD, Professor, Collective Health Institute, School of Medicine - Federal University of Bahia.

*** Radiologist, Delfin Clinic - Imaging Diagnosis.

$* * * *$ Chairman, Department of Radiology, School of Dentistry, University of São Paulo.
} 
Mariz ACR, Campos PSF, Sarmento VA, Gonzalez MOD, Panella J, Mendes CMC. Assessment of disk displacements of the temporomandibular joint. Braz Oral Res 2005;19(1):63-8.

\section{INTRODUCTION}

Internal derangement (ID) of the temporomandibular joint (TMJ) is characterized by an abnormal relationship between the articular disk and the condyle, the glenoid fossa, and the articular eminence $^{20}$. It is mostly caused by disk displacement (DD) and jeopardizes the function of the $\mathrm{TMJ}^{9}$, although DD may be present without TMJ dysfunction. In addition, there are other etiologic factors related to ID, such as adhesions, loose bodies inside the articular spaces, and inflammatory and degenerative diseases ${ }^{9}$.

Due to its accuracy, magnetic resonance imaging (MRI) has become the first choice examination for the diagnosis of alterations of the TMJ, mostly soft tissue alterations, making the precise evaluation of the articular disk position possible ${ }^{13,15,18}$, and thus allowing the diagnosis of disk displacement $^{3,18}$. Furthermore, magnetic resonance (MR) images give information about the cortical and medullary bones ${ }^{8,12,13}$, disk degeneration and articular effusion ${ }^{12}$, and about the bilaminar zone ${ }^{12,19}$. For these reasons, MRI is now the gold standard for the diagnosis of $\mathrm{ID}^{12,21}$.

The aim of this study was to assess TMJ disk displacements in patients who had been referred for MRI scans. The following data were recorded: the type and prevalence, distribution according to gender, age and affected side, reciprocal clicking, pain, range of the mouth opening movement and dental condition.

\section{MATERIALS AND METHODS}

The MR images of the TMJ of 113 patients, $92(81.4 \%)$ females and 21 (18.6\%) males, ages from 12 to 78 years (mean age $36.4 \pm 13.5$ ), were appraised from July 2001 to December 2002. Images were obtained according to the parameters described in Table 1.

As a rule, the clinical examination included directing the anamnesis of all the subjects to the main complaint and TMJ palpation during maximum mouth opening movement.

The MR scans were made using a Signa Horizon system model scanner (General Electric, Milwaukee, WI, USA), at a magnetic field magnitude of $1.5 \mathrm{~T}$, using a bilateral radiofrequency surface coil of $6.5 \times 6.5 \mathrm{~cm}$ in size.

For the acquisition of the final scan in $\mathrm{T} 1$, an axial scout was performed. Based on that, the condyle was located and the right orientation of the parasagittal and paracoronal slice sequences was established.

The scans were interpreted by two experienced radiologists who used the same criteria for DD diagnosis as that proposed by Katzberg, Westesson ${ }^{9}$ (1994) and Milano et al. ${ }^{12}$ (2000).

The statistical analysis, with a level of significance of 5\%, comprised the Pearson's chi-squared test to observe the relation between the variables, measured at the minimum on an ordinal scale, and the Cuzick's test to evaluate the tendency of the variable age (grouped in age ranges) between the groups with and without DD. The prevalence and prevalence reasons were estimated as occurrence measurements and epidemiological associations.

\section{RESULTS}

The results of this study are shown in Tables 2 to 9 . Ninety $(79.7 \%)$ patients presented with DD. Anterior DD, with or without reduction, corresponded to $55(61.1 \%)$ of the cases with DD [45 $(81.8 \%)$ females and $10(18.2 \%)$ males].

\section{DISCUSSION}

Of the total sample of 113 patients, 90 (79.7\%) patients presented with DD. This result is similar to the results of Ishigaki et al. ${ }^{7}$ (1992) $(72.2 \%)$ and Paesani et al. ${ }^{14}$ (1992) (78\%), who worked with arthrography and arthrography plus MRI, respectively. Due to its invasive and painful characteristics, and sometimes unsatisfactory results, arthrogra-

TABLE 1 - Parameters for obtaining TMJ T1-weighted and proton density-weighted sequences.

\begin{tabular}{l|c|c|c|c|c|c|c}
\hline \multicolumn{1}{c|}{ Image } & TR (ms) & TE $(\mathrm{ms})$ & NEX & FOV $(\mathrm{cm})$ & $\begin{array}{c}\text { Slice thickness } \\
(\mathrm{mm})\end{array}$ & Matrix & Time \\
\hline Axial localizer (closed-mouth) & 400 & 13 & 1 & 20 & 4 & $256 \times 128$ & $57 \mathrm{~s}$ \\
\hline T1 parasagittal (closed-mouth) & 450 & 13 & 5 & 14 & 2 & $256 \times 256$ & $4 \mathrm{~min} 7 \mathrm{~s}$ \\
\hline T1 parasagittal (open-mouth) & 450 & 13 & 5 & 14 & 2 & $256 \times 256$ & $4 \mathrm{~min} 7 \mathrm{~s}$ \\
\hline DP paracoronal (closed-mouth) & 1,750 & 17 & 5 & 12 & 2 & $256 \times 256$ & $2 \mathrm{~min} 23 \mathrm{~s}$ \\
\hline \hline
\end{tabular}

TMJ: temporomandibular joint; TR: repetition time; TE: echo time; NEX: number of excitations; FOV: field of view; DP: proton density. 
Mariz ACR, Campos PSF, Sarmento VA, Gonzalez MOD, Panella J, Mendes CMC. Assessment of disk displacements of the temporomandibular joint. Braz Oral Res 2005;19(1):63-8.

TABLE 2 - DD distribution according to gender and affected side.

\begin{tabular}{l|c|c|c|cc}
\hline \hline \multicolumn{1}{c|}{ Gender } & Unilateral DD right side (\%) & Unilateral DD left side (\%) & Bilateral DD (\%) & \multicolumn{2}{c}{ Total (\%) } \\
\hline Female & $13(14.4)$ & $10(11.1)$ & $51(56.7)$ & 74 & $(82.2)$ \\
\hline Male & $0(0.0)$ & $4(4.5)$ & $12(13.3)$ & 16 & $(17.8)$ \\
\hline Total & $13(14.4)$ & $14(15.6)$ & $63(70.0)$ & $90(100.0)$ \\
\hline \hline
\end{tabular}

DD: disk displacement.

TABLE 3 - DD distribution according to age.

\begin{tabular}{|c|c|c|c|c|}
\hline Age & Unilateral DD right side (\%) & Unilateral DD left side (\%) & Bilateral DD (\%) & Total $(\%)$ \\
\hline $11-20$ & $2 \quad(2.2)$ & $3 \quad(3.3)$ & $9(10.0)$ & $14 \quad(15.6)$ \\
\hline $21-30$ & $1 \quad(1.1)$ & $3 \quad(3.3)$ & $14(15.6)$ & $18 \quad(20.0)$ \\
\hline $31-40$ & $3 \quad(3.3)$ & $3 \quad(3.3)$ & $19(21.1)$ & $25 \quad(27.8)$ \\
\hline $41-50$ & $5 \quad(5.6)$ & $4 \quad(4.4)$ & 11 (12.2) & $20 \quad(22.2)$ \\
\hline $51-60$ & $2 \quad(2.2)$ & $1 \quad(1.1)$ & $8 \quad(8.9)$ & $11 \quad(12.2)$ \\
\hline$>61$ & $0 \quad(0.0)$ & $0 \quad(0.0)$ & $2 \quad(2.2)$ & $(2.2)$ \\
\hline Total & $13(14.4)$ & $14(15.6)$ & $63(70.0)$ & $90(100.0)$ \\
\hline
\end{tabular}

DD: disk displacement.

TABLE 4 - Distribution of the sample according to the presence or absence of RC and DD.

\begin{tabular}{l|c|c|cc}
\hline \hline & With RC (\%) & Without RC (\%) & \multicolumn{2}{|c}{ Total (\%) } \\
\hline With DD & $62(54.9)$ & $28(24.8)$ & $90(79.7)$ \\
\hline Without DD & $11(9.7)$ & $12(10.6)$ & $23(20.3)$ \\
\hline Total & $73(64.6)$ & $40(35.4)$ & $113(100.0)$ \\
\hline \hline
\end{tabular}

RC: reciprocal clicking; DD: disk displacement.

TABLE 5 - Distribution of the sample according to the presence or absence of RC and anterior DD with reduction.

\begin{tabular}{l|c|c|cc}
\hline \hline & With RC (\%) & Without RC (\%) & \multicolumn{2}{|c}{ Total (\%) } \\
\hline Positive to anterior DD with reduction & $26(23.0)$ & 7 & $33(29.2)$ & $(29.2)$ \\
\hline Negative to anterior DD with reduction & $47(41.6)$ & $33(29.2)$ & $80(70.8)$ \\
\hline Total & $73(64.6)$ & $40(35.4)$ & $113(100.0)$ \\
\hline
\end{tabular}

RC: reciprocal clicking; DD: disk displacement.

TABLE 6 - Distribution of the sample according to the presence or absence of RC and anterior DD without reduction.

\begin{tabular}{l|c|r|r}
\hline \hline & With RC (\%) & Without RC (\%) & Total (\%) \\
\hline Positive to anterior DD without reduction & $20(17.7)$ & $8 \quad(7.1)$ & 28 \\
\hline Negative to anterior DD without reduction & $53(46.9)$ & $32(28.8)$ & 85 \\
\hline Total & $73(64.6)$ & $40(35.4)$ & $113(100.0)$ \\
\hline \hline
\end{tabular}

RC: reciprocal clicking; DD: disk displacement. 
Mariz ACR, Campos PSF, Sarmento VA, Gonzalez MOD, Panella J, Mendes CMC. Assessment of disk displacements of the temporomandibular joint. Braz Oral Res 2005;19(1):63-8.

TABLE 7 - Distribution of the sample according to the presence or absence of JOL and DD.

\begin{tabular}{l|c|c|cc}
\hline \hline & With JOL (\%) & Without JOL (\%) & \multicolumn{2}{|c}{ Total (\%) } \\
\hline With DD & $26(23.0)$ & $64(56.6)$ & $90(79.6)$ \\
\hline Without DD & $6(5.3)$ & $17(15.0)$ & $23 \quad(20.4)$ \\
\hline Total & $32(28.3)$ & $81(71.7)$ & $113(100.0)$ \\
\hline
\end{tabular}

JOL: jaw opening limitation; DD: disk displacement.

TABLE 8 - Distribution of the sample according to the presence or absence of JOL and anterior DD without reduction.

\begin{tabular}{l|c|c|c}
\hline \hline & With JOL (\%) & Without JOL (\%) & Total (\%) \\
\hline Positive to anterior DD without reduction & $13(11.5)$ & $15(13.3)$ & $28(24.8)$ \\
\hline Negative to anterior DD without reduction & $19(16.8)$ & $66(58.4)$ & $85(75.2)$ \\
\hline Total & $32(28.3)$ & $81(71.7)$ & $113(100.0)$ \\
\hline \hline
\end{tabular}

JOL: jaw opening limitation; DD: disk displacement.

TABLE 9 - Distribution of the sample according to the oral condition and DD.

\begin{tabular}{l|c|c|cc}
\hline \hline & Full dentition (\%) & Incomplete dentition (\%) & \multicolumn{2}{|c}{ Total (\%) } \\
\hline With DD & $24(21.2)$ & $66(58.4)$ & $90(79.7)$ \\
\hline Without DD & $5(4.4)$ & $18(15.9)$ & $23(20.3)$ \\
\hline Total & $29(25.7)$ & $84(74.3)$ & $113(100.0)$ \\
\hline \hline
\end{tabular}

DD: disk displacement.

phy is not a current option for TMJ examination, although it provides high quality images for disk perforation.

The findings on disk displacement type were as follows: anterior DD, with or without reduction, was found in $55(61.1 \%)$ of the cases with DD [45 (81.8\%) females and 10 (18.2\%) males]. Our data agree with the results reported in the related literature ${ }^{9}$, which do not demonstrate a higher prevalence of anterior DD. In our opinion, the action of the lateral pterygoid muscle is a contributory etiologic factor and it determines a tendency towards anterior DD.

Even though the greater number of patients presenting with DD were female (Table 2), this difference was not statistically significant $(p=0.66)$. In contrast, some authors ${ }^{4,6,7,17}$ found that DD is more common in females, while Kircos et al. ${ }^{11}$ (1987) found that males are more frequently affected by the condition. With these conflicting results, environmental and even genetic factors may determine different characteristics in different populations.

A statistically significant association $(p=0.37)$ between DD and increased age was not observed (Table 3). According to Sanchez-Woodworth et al. ${ }^{17}$
(1988), TMJ internal derangement may also involve children and Isberg et al. ${ }^{6}$ (1998) observed a statistically significant incidence of symptomatic DD in male and female adolescents. In fact, $15.6 \%$ of our sample comprised patients in the 11-20-year-old age group, although the majority of the patients were aged $31-40$ or $>41$.

Regarding its uni- or bilateral occurrence (Table 3), DD was observed only on the right side in $13(14.4 \%)$ patients; and on the left side in 14 $(15.6 \%)$ patients. More than half the patients with DD (63 patients - 70\%) presented with bilateral $\mathrm{DD}$, and this difference was statistically significant $(\mathrm{p}<0.01)$. This result, in association with the observation of Milano et al. ${ }^{12}$ (2000), who found that $80 \%$ of their patients were affected by bilateral DD, gives support to the inference of Crusoé-Rebello et al. ${ }^{2}$ (2003), who stated that both TMJs constitute only one functional unit. Therefore, contralateral TMJs tend to be equally affected by DD.

Reciprocal clicking (RC) was observed in patients with and without DD. Seventy-three (64.6\%) patients presented with RC. Sixty-two (54.9\%) patients displayed DD with RC, while 11 (9.7\%) patients showed RC without DD (Table 4). 
Mariz ACR, Campos PSF, Sarmento VA, Gonzalez MOD, Panella J, Mendes CMC. Assessment of disk displacements of the temporomandibular joint. Braz Oral Res 2005;19(1):63-8.

A statistically significant association $(p=0.004)$ between RC and anterior DD with reduction was observed (Table 5). Nevertheless, a statistically significant association $(p=0.38)$ between RC and anterior DD without reduction was not observed (Table 6). These data lead us to infer that RC strongly suggests anterior DD with reduction. As RC in association with anterior DD without reduction may occur, the existence of $\mathrm{RC}$ is not conclusive for anterior DD with reduction. On the other hand, RC may be present without DD, which is in agreement with Katzberg, Westesson ${ }^{9}$ (1994), who found that morphologic alterations of the articular disk give rise to RC and may determine irregular movement of the mandible upon jaw opening.

There was no statistically significant association between DD and pain, be it articular or facial pain, otalgia or cephalgia $(\mathrm{p}=0.63,0.21,0.15$, and 0.3 , respectively).

Anterior DD, the commonest type, may cause posterior disk attachment between the condyle and the temporal component. As a consequence, the condyle exerts pressure on the disk attachment, an enervated and vascularized structure, and thus, anterior DD is initially present in association with articular pain. With the evolution of the condition, there is usually, but not always, fibrosis of the disk attachment and the articular pain gradually disappears. However, in a few cases, fibrosis does not occur and it is possible to observe a hyperplastic, highly vascularized, and chronically inflamed posterior disk attachment associated with chronic articular pain. In addition, degenerative conditions related to articular pain are usually secondary to anterior DD without reduction ${ }^{9}$. Therefore, anterior DD may be painful at first, evolve to a painless period, and, rarely, become a chronic painful condition.

Among the cases with DD in or study, the high number of patients with symptomatic DD aged 1120 years ( 14 patients $-15.6 \%)$ is in agreement with the findings of Isberg et al. ${ }^{6}$ (1998), who found that symptomatic DD mostly affects adolescents. In our opinion, the main reason for the lack of association between DD and pain is the number of patients $(62.2 \%)$ aged between 31 and 60 years, when the articular condition is diagnosed in a chronic symptomless stage.

Jaw opening limitation (JOL) was found in patients with DD (26 patients - 23\%) and in patients without DD (6 patients - 5.3\%). There was no statistically significant association $(p=0.79)$ between JOL and DD (Table 7). Nevertheless, a statistically significant association $(p=0.01)$ between JOL and anterior DD without reduction was observed (Table 8).

Even though anterior DD without reduction is not a jaw opening limitation factor for some patients, we observed that, for a large number of patients, anterior DD without reduction is related to mouth opening limitation. This was also observed by Katzberg et al. ${ }^{10}$ (1996).

Incomplete dentition was found in $66 \mathrm{DD}$ patients and in 18 non-DD patients. This difference was not statistically significant $(p=0.629)$. These results (Table 9) minimize the importance of occlusal trauma as an etiologic factor.

In contrast with the findings of Harriman et al. ${ }^{5}$ (1990), who observed a statistically significant association between TMJ dysfunction and loss of teeth, we believe, in agreement with the findings of Pullinger et al. ${ }^{16}$ (1993) and Ciancaglini et al. ${ }^{1}$ (1999), that loss of teeth is a contributory, but not determining, factor acting in the pathophysiology of TMJ internal derangement.

\section{CONCLUSIONS}

Based on our results, the following conclusions can be reached:

1. Anterior disk displacement is the most prevalent type of articular disk displacement.

2. Males and females are equally affected by the condition.

3. There is no statistically significant association between disk displacement and increased age.

4. Bilateral disk displacement is the most prevalent occurrence.

5. There is a statistically significant association between anterior disk displacement with reduction and reciprocal clicking.

6. There is no statistically significant association between disk displacement and pain, be it articular or facial pain, otalgia or cephalgia.

7. There is a statistically significant association between anterior disk displacement without reduction and jaw opening limitation.

8. There is no statistically significant association between disk displacement and dental condition (full or incomplete dentition).

\section{ACKNOWLEDGMENTS}

We sincerely appreciate the trust and collaboration offered by Dr. Delfin Gonzalez Miranda, who has made this research possible. 
Mariz ACR, Campos PSF, Sarmento VA, Gonzalez MOD, Panella J, Mendes CMC. Assessment of disk displacements of the temporomandibular joint. Braz Oral Res 2005;19(1):63-8.

\section{REFERENCES}

1. Ciancaglini R, Gherlone EF, Radaelli G. Association between loss of occlusal support and symptoms of functional disturbances of the masticatory system. J Oral Rehabil 1999;26(3):248-53.

2. Crusoé-Rebello IMR, Campos PSF, Rubira IRF, Panella $\mathrm{J}$, Mendes CMC. Evaluation of the relation between the horizontal condylar angle and the internal derangement of the TMJ - a magnetic resonance imaging study. Pesqui Odontol Bras 2003;17(2):176-82.

3. De Mot DB, Casselman J, Widelec J. L'imagerie de l'articulation temporo-mandibulaire. Rev Belg Méd Dent 1997;52(1):283-303.

4. Donegá SHP, Cardoso R, Procópio ASF, Luz JGC. Análise da sintomatologia em pacientes com disfunções intra-articulares da articulação temporomandibular. Rev Odontol Univ São Paulo 1997;11:77-83.

5. Harriman LP, Snowdon DA, Messer LB, Rysavy DM, Ostwald SK, Lai C, et al. Temporomandibular joint dysfunction and selected health parameters in the elderly. Oral Surg Oral Med Oral Pathol Oral Radiol Endod 1990;70(4):406-13.

6. Isberg A, Hägglund M, Paesani D. The effect of age and gender on the onset of symptomatic temporomandibular joint disk displacement. Oral Surg Oral Med Oral Pathol Oral Radiol Endod 1998;85(3):252-7.

7. Ishigaki S, Bessette RW, Maruyama T. The distribution of internal derangement in patients with temporomandibular joint dysfunction - prevalence, diagnosis, and treatments. Cranio 1992;10(4):289-96.

8. Katzberg RW, Schenck J, Roberts D, Tallents RH, Manzione JV, Hart HR, et al. Magnetic resonance imaging of the temporomandibular joint meniscus. Oral Surg Oral Med Oral Pathol Oral Radiol Endod 1985;59(4):332-5.

9. Katzberg RW, Westesson P. Diagnosis of the temporomandibular joint. Philadelphia: W. B. Saunders Company; 1994.

10. Katzberg RW, Westesson PL, Tallents RH, Drake CM. Orthodontics and temporomandibular joint internal derangement. Am J Orthod Dentofacial Orthop 1996;109(5):515-20.

11. Kircos LT, Ortendahl DA, Mark AS, Arakawa M. Magnetic resonance imaging of the TMJ disc in asymptomatic volunteers. J Oral Maxillofac Surg 1987;45(10):852-4.

12. Milano V, Desiate A, Bellino R, Garofalo T. Magnetic resonance imaging of temporomandibular disorders: classifi- cation, prevalence and interpretation of disc displacement and deformation. Dentomaxillofac Radiol 2000;29(6):352-61.

13. Nebbe B, Brooks SL, Hatcher D, Hollender LG, Prasad NGN, Major PW, et al. Magnetic resonance imaging of the temporomandibular joint: Interobserver agreement in subjective classification of disk status. Oral Surg Oral Med Oral Pathol Oral Radiol Endod 2000;90(1):102-7.

14. Paesani D, Westesson PL, Hatala M, Tallents RH, Kurita K. Prevalence of temporomandibular joint internal derangement in patients with craniomandibular disorders. Am J Orthod Dentofacial Orthop 1992;101(1):41-7.

15. Pieruci P, Chassagne JF, Briche D, Dinh Doan G. L'intérêt de l'IRM dans la visualisation du ménisque des articulations temporo-mandibulaires (A.T.M.). Rev Stomatol Chir Maxillofac 1991;92(3):149-54.

16. Pullinger AG, Seligman DA, Gornbein JA. A multiple logistic regression analysis of the risk and relative odds of temporomandibular disorders as a function of common occlusal features. J Dent Res 1993;72(6):968-79.

17. Sanchez-Woodworth RE, Katzberg RW, Tallents RH, Guay JA. Radiographic assessment of temporomandibular joint pain and dysfunction in the pediatric age-group. ASDC J Dent Child 1988;55(4):278-81.

18. Sano T. Recent developments in understanding temporomandibular joint disorders. Part 1: bone marrow abnormalities of the mandibular condyle. Dentomaxillofac Radiol 2000;29(1):7-10.

19. Sano T. Recent developments in understanding temporomandibular joint disorders. Part 2: changes in the retrodiscal tissue. Dentomaxillofac Radiol 2000;29(5):260-3.

20. Tallents RH, Katzberg RW, Murphy W, Proskin H. Magnetic resonance imaging findings in asymptomatic volunteers and symptomatic patients with temporomandibular disorders. J Prosthet Dent 1996;75(5):529-33.

21. Tasaki MM, Westesson PL, Isberg AM, Ren YF, Tallents $\mathrm{RH}$. Classification and prevalence of temporomandibular joint disk displacement in patients and symptom-free volunteers. Am J Orthod Dentofacial Orthop 1996;109(3):249-62. 